\title{
Application of UAS and Revit for Pipeline Design
}

\author{
Hamlet Reynoso Vanderhorst ${ }^{1}$, David Heesom², Subashini Suresh ${ }^{3}$, Suresh Renukappa ${ }^{4}$ \\ and Keith Burnham ${ }^{5}$
}

1 University of Wolverhampton, Wolverhampton, UK, (corresponding author)

h.d.reynosovanderhorst@w/v.ac.uk

2 University of Wolverhampton, Wolverhampton, UK, d.heesom@wlv.ac.uk

3 University of Wolverhampton, Wolverhampton, UK, s.subashini@wlv.ac.uk

4 University of Wolverhampton, Wolverhampton, UK, suresh.renukappa@wlv.ac.uk

5 University of Wolverhampton, Wolverhampton, UK, k.burnham@wlv.ac.uk

\begin{abstract}
The professionals in the vertical and horizontal construction have tested methods to enhance the quality, safety, environmental impact, delivery time and cost control in their works promoted in learning organisations. Automation strategies applying robots and technology has been a focal point in industry of manufacture by its benefits in productivity levels and quality of works, and in some cases, without affecting other factors in a long-term period. The construction industry is playing a predominant economic heading in certain countries. Therefore, the adoption of Unmanned Aerial System (UAS) and Building Information Modelling (BIM) methodology as an automation strategy represent in short and long terms positive economic impact. UAS or drones have been used for cargo and data capturing in the built environment. Nowadays, the construction of infrastructures is the most benefited project from UAS implementations by gathering visual data of cracks, obstructions, energy levels, traffic and current conditions of the projects fulfilling the gap of human risks reduction, speed on data collection, and digitalisation of the real-world along with BIM. However, there is a breach in reliability and awareness on the UAS application cases in the infrastructure sector.

The aim of this paper is to present the reasons and the application case of the UAS from the topography department of a Water Supply public organisation. The findings show that the UAS achieved a higher level of productivity and efficiency in the daily pre-construction works for designing pipelines. The case covers sewer identification and georeferencing in rural areas where the satellites were unavailable to show the state accurately. The tool used was an RTK DJI Phantom 4 to survey the site conditions in BIM format. The integration of UAS in BIM showed a higher level of productivity and efficiency in the employee's workflow in terms of data collection contrasting to old-fashion methods.
\end{abstract}

(C) 2020 The Authors. Published by Budapest University of Technology and Economics \& Diamond Congress Ltd Peer-review under responsibility of the Scientific Committee of the Creative Construction Conference 2020.

Keywords: survey, infrastructure, BIM, UAS, water supply

\section{Introduction}

Bridges, roads, railways, tunnels, water supply, sewers, electrical grid and telecommunications are infrastructures that underpin urban and rural services over a considerable period. Nowadays, infrastructure assets demand costly and extensive processes of construction, maintenance, inspections, rehabilitation, and restoration. The current workflows to survey the facilities involve high-risk exposure of the personnel, utilisation of site specialised machinery, exhausting walking distances, fastidious traffic diversion, and environmental impact which can significantly impact the productivity, quality, and cost of the 
projects. Therefore, automation strategy is required to provide trustworthy, durable records and resource maximisation of the public assets.

The built environment investments, in some nations, represent up to $50 \%$ of their national budget, indicating to be a sector to be optimised. However, tools and software have emerged to fill the gap in productivity as an Unmanned Aerial System (UAS) or drones integrated into Building Information Modeling (BIM). Several developed countries have applied automation strategies in the built environment through digitalisation. They are promoting efficiency in construction project data creation, storage and modification. Researchers well understand that on a long-term basis, construction digitisation presents positive evidence of increasing transparency levels, productivity and effectiveness on the projects schedules and cost management [1].

In the context of developing countries, the adoption of technologies can be reduced or minimal. The National Institute of Potable waters and Sewerage (INAPA) is a public institution in the Dominican Republic intending to consolidate an automation strategy utilising UAS. INAPA is responsible for meeting the needs and demands of the urban and rural population of the country with adequate non-potable water, sewers waters services, residual treatment plants and to develop and approve plans. Therefore, the department of topography is in charge of: gathering georeferenced terrain elevation data; locating pure water sources, ubicate the conditions of the sewer; calculate, design, inspect, and redesign parts or the entire infrastructure, the buildings concerned to the water supply source in the country. The department inspects, builds, rehabilitates, and redesigns aqueduct, sewerage system, water treatment and offices in the countryside division. The department manages a large number of projects and subsequently is seeking to incorporate an automation strategy throughout UAS and BIM application by the following reasons: facilitate easier and faster sharable visual data of the working process, Increment workers safety against hazard environment effects and climate change effects; boost the productivity in their workflows to achieve the annual institution's goals on budget; obtain a higher level of details and accuracy of the terrain models, project site and incorporate visual records of the progressed accomplishment; foment the reliability and transparency of the work process, site conditions and environmental concerns related to the external factors and impacts of the projects; implement innovation as a functional and creative approach for construction solutions to the quotidian works.

The traditional workflows in the institution operate in not-automatic for site condition inspections, surveys and 2D CAD design. These approaches inherently produce several delays in the water supply systems in the context of reparation and supply demands. The aim of this paper is to report a comparative analysis of the existing traditional methods of developing a water supply design against the case of UAS in BIM integration in the current workflow. By using a real-world project and data, the work seeks to contrast the productivity increase rate when UAS is used as opposed to traditional approaches.

\section{Literature review}

The application of aerial robots' has been explored in various industries to identify their effectiveness in the last 5 years. Most recently, aerial robots have been applied for spray disinfectant for COVID-19 in China, Cargo biological samples in the Dominican Republic, and determinate culture hydration levels in the agricultural field in Brazil. In contrast to the built environment, which the drone is mostly applied for visualisation and mapping. In any context, the UAS is applied with the aim to: reduce human risk exposure; use as a transport, digitiser and data record, then finally gather faster and numerous data from the environment that with the current instrument could not be possible to reach. However, the maturity in the UAs application relies on sensors and capabilities.

\subsection{Unmanned Aerial System}

The Unmanned Aerial System (UAS) or drone operates in three modes: manual, semi-autonomous and autonomous according to the manufacturer physical and software designs. The unpiloted aircraft is capable, per se, to transport sensors or goods. The sensors selection criteria perform a predominant role in infrastructures tasks assessments. Sensors such as GPS, thermal camera, RBG camera and LIDAR sensors enable crack inspections, energy monitoring, traffic monitoring and assets allocation in and around projects [2]. The visual data produced by RGB camera and thermal sensors endorse the tasks and data analysis compromising an adoption or not of a strategy. The UAS capture images that can be administered for the 
different department on the institution as the essential step and 3D reconstruction of the site for a more detailed and technical overview [3]. The integration of digital strategies based on emerging technologies pave the concepts of digital designs, processes, technologies, and finally, the shift paradigms of new workflows adoption as the integration of 3D models.

\subsection{Infrastructure projects}

In the infrastructure sector, the frequent applications of UAS are focused on bridge inspections undertaking cracks inspections and 3D reconstruction tasks [4] [5] [6] [7], in water supply quantification of damages by natural events and infrastructure maintenance [8] [9] [10]. In the case of roads pavement [11], electrical grids [12] [13], telecommunication, railway, tunnels [14] and sewers identification [15] there is a gap in scientific literature and maturity of the UAS operation. Furthermore, the current implementations are focused on reducing human risk exposure, gather and digitalise data for specific tasks and increase the amount and speed data in projects. The 3D reconstruction of the infrastructure allows generating a virtual representation of the geometry embedded in the infrastructure and compared with the actual designs. The UAS enables the Building Information Modelling data to be visualised in 3D, added parametric information, and provide as-built geometry. The role of UAS is filling the gap in automating reconstruction of the physical world into 3D digital format instead to be designing from 2D CAD or abstracts representations. Generally, the commercial software packages involved in 3D BIM are commonly Revit, Civil 3D, and Rinho, which drives the designs and monitor records during the construction project execution.

\section{Research methodology}

The aim of this paper is to present a comparative analysis of the existing traditional methods of developing a water supply design against the case of UAS approach in the current organisation workflow. The illustrative case of study investigates the contrast of productivity rate between traditional and digital survey method. The hypothesis was regarding UAS effectiveness to reduce time in the department. Therefore, the UAS approach can improve the accuracy and speed of designing process reconstructing visual data and adding to a digital platform or BIM.

\subsection{Traditional methodology}

The actual design method is carried out with an RTK station on site. Previous assessments used to be taken by google maps facing the challenges of accuracy and clarity of the sites. The google historical design data against the old storage images on the computer provoked productivity issues in the department. Therefore, the team of engineers used to travel to the site and identify the path segments to be surveyed. Manual sewers georeferencing is usually taken to locate the GPS coordinates in the map. Sometimes, the process gets confusing by the different stakeholders involved in the project. Then, the results were configurated into a spreadsheet file and exported into the 2D CAD designs in Civil 3D. As a result, the speed of the process created delays, communication issues and long waits for communities to receive the water services. Then, the idea of UAS was examined to improve productivity.

\subsection{UAS workflow integration}

The literature presents the cases of sewers location [15], road pavement [11], dams inspections [9] and the frameworks of UAS bridge inspections, [4]; undertaking a UAS 2D and 3D approach according with the task to be addressed [3]. Therefore, the framework of the automation process lies in the decision to adopt strategies thought digitalisation with- and without reality reconstruction. In the majority of the cases, the 3D reconstruction is used to provide a more significant amount of data that support site overview, measurements and capabilities. For this project, the approach was proofing the effectiveness of the UASimaging assessment to the department. The workflow presented in Fig. 1. express the process of UAS integration for infrastructure projects. 


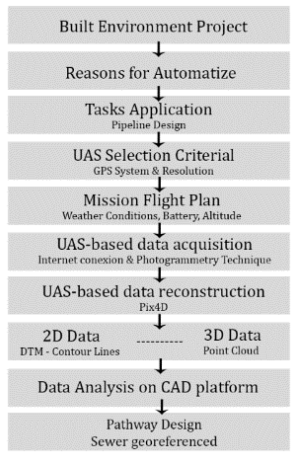

Fig. 1. Typical Workflow of UAS application

\subsection{UAS data reconstruction}

The pathway was delimited to $1.3 \mathrm{~km}$ area where was needed the water pipeline supply. Seven ground control points were used as confirmation points between the model distances. Using the data captured from the UAS, a Digital Elevation Model (DEM) and a Digital Terrain Model (DTM) were generated to identify the field conditions (Fig. 2.) and extract the contour lines. Technical aspects of urban planning were considered for future site demands, land usage and human mobility-the point cloud generated with a 0.0018 distance between points allowed to produce 3D $0.2 \mathrm{~m}$ distance contour lines. The DTM was passed to Qgis where the contour lines were generated and exported to Autodesk Civil 3D to reconstruct the terrain in Revit as a topography surface finally. The contour lines were superposed to identify the pipeline pathway line. Then, the contour lines were overlaid on the DTM appreciating the soft terrain pathway.
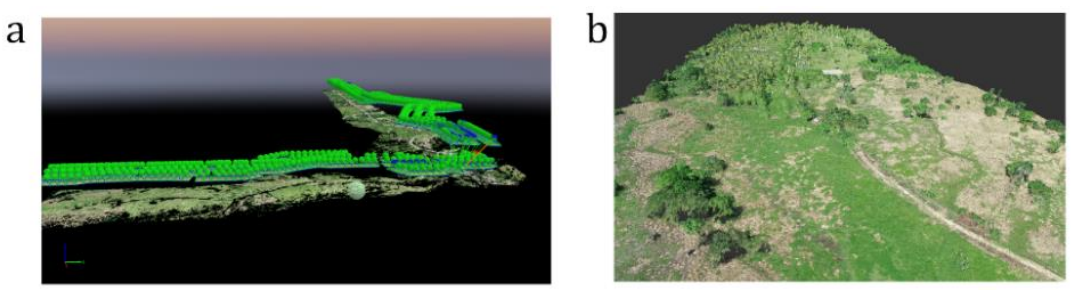

Fig. 2. (a) Photogrammetry 3D Reconstruction; (b) Site 3D view

The cross-section was extracted taking the civil 3D (Fig. 3. (d)) software and then, suggested to be reconstructed in Revit (Fig. 4. (c)) to visualise and quantify the material requirements. The 2D and 3D of the site allowed the engineers and architects to understand the irregularities of the area, identify current issues within the site boundary. Besides, the design contemplates the environment conditions, traffic congestion by the airport proximity and the impact on existing infrastructures.
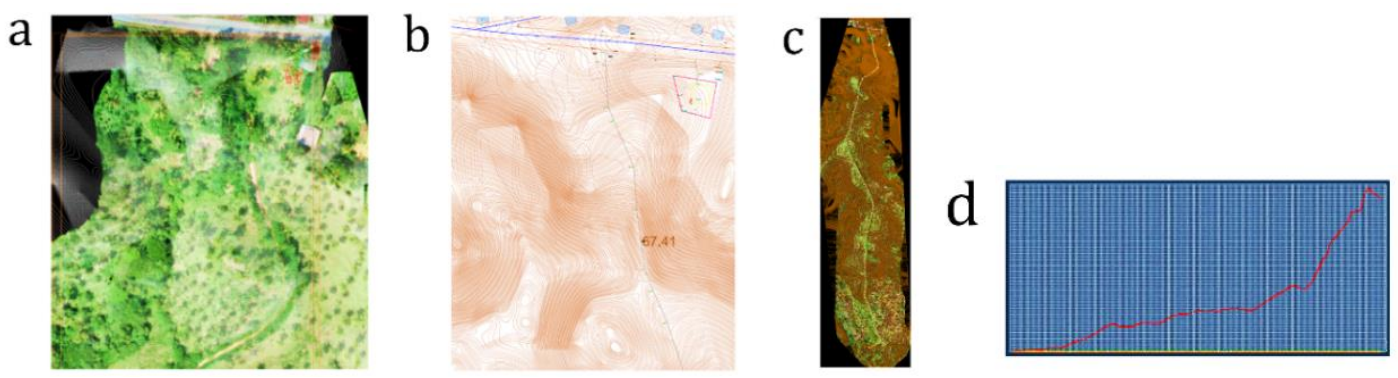

Fig. 3. (a) Segment of the 2D orthomosaic overlaid with the pipeline design; (b) Contour lines, altitude points lines, blue square are houses, the pink polygon is the main reservoir, black lines indications of street edges; (c) Overview of the pathway and highresolution image; (d) cross-section of the path.

Furthermore, the Pix4D software was used to visualise and georeference the sewers and their conditions (Fig. 4. a, b). The 3D reconstruction of this element allowed the engineers to locate the conditions and step into rehabilitation if it was required. 

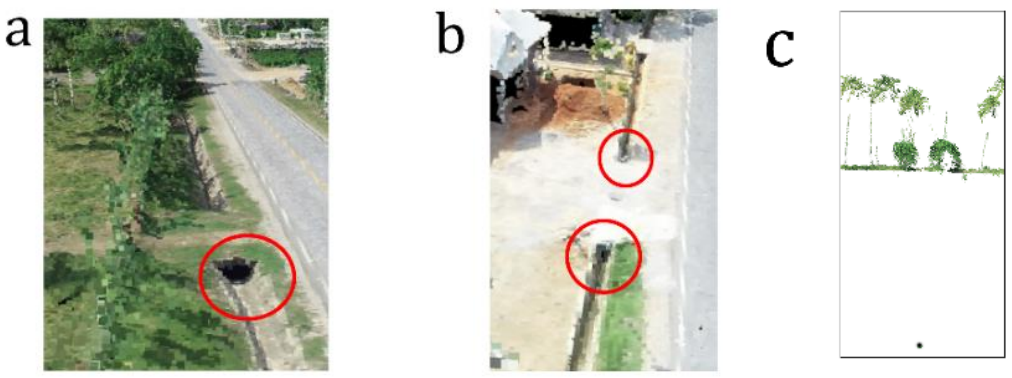

Fig. 4. (a) Sewer identification status; (b) identification of possible obstruction of the sewers by construction works; (c) Point Cloud up to the Pipeline location

\section{Comparative workflow}

The workflow implemented to allow the organisation to present a significant amount of time and resources during the topography works. As shown in table 3 and 4, the major contribution of the implementation is observed in the initial stages.

Table 3. Traditional Pipeline Design Workflow

\begin{tabular}{llllll}
\hline Project Phase & Description & Days & Personnel & Effort & Total \\
\hline Data Capture & $\begin{array}{l}\text { Field-based RTK } \\
\text { survey }\end{array}$ & 6 & 4 & 24 & 24 \\
$\begin{array}{l}\text { Survey } \\
\text { Processing }\end{array}$ & $\begin{array}{l}\text { Data arrangement } \\
\text { for Cross-section } \\
\text { develomment in } \\
\text { Excel }\end{array}$ & 1 & 1 & 1 & \\
& $\begin{array}{l}\text { Topographic point } \\
\text { processing }\end{array}$ & 1 & 1 & 1 & 4 \\
$\begin{array}{l}\text { Contour line } \\
\text { Generation }\end{array}$ & 2 & 1 & 2 & \\
$\begin{array}{l}\text { Pipeline } \\
\text { Design }\end{array}$ & 2D Plan draughting & 7 & 1 & 7 & 7 \\
\hline
\end{tabular}

Table 4. UAS-BIM Pipeline Design Workflow

\begin{tabular}{llllll}
\hline Project Phase & Description & Days & Personnel & Effort & Total \\
\hline Data Capture & UAV Flight & 1 & 1 & 1 & 1 \\
$\begin{array}{l}\text { Survey } \\
\text { Processing }\end{array}$ & $\begin{array}{l}\text { Point Cloud and } \\
\text { Contour Generation }\end{array}$ & 1 & 1 & 1 & \\
& $\begin{array}{l}\text { Topographic surface } \\
\text { creation } \\
\text { Cross / Long Section } \\
\text { Creation }\end{array}$ & 0.5 & 1 & 0.5 & 3.5 \\
Pipeline & $\begin{array}{l}\text { Creation of the 3D } \\
\text { Gesign } \\
\text { and BlM Alic Alignment }\end{array}$ & 7 & 1 & 7 & 7 \\
\hline
\end{tabular}

The results demonstrate an overall effort reduction of nearly $69 \%$ concerning the entire pipeline design process. A significant decrease of $96 \%$ in the effort is identified in the data acquisition. In addition to the initial, $25 \%$ in the overall process was reduced. Moreover, the new approach brought visual information regarding the conditions that routine survey works may not be carrying in.

\section{Conclusion}

The application of UAS workflow in BIM increases the productivity and quality of the pipeline design work. The implementation of the UAS improved the accuracy and speed of the design process. The surveying and $3 \mathrm{D}$ reconstruction of the site have been the biggest contribution to the automation strategy. The Cross sections used to be developed from the RTK survey, now are generated directly from either a point cloud or orthomosaic. It was permitted to manage a higher amount of data and facilitate information transfer between different departments. Furthermore, software as Pix4D allowed identifying the current conditions of sewers and their GPS location. Future works are focus on exploring the interoperability between software platforms and the integration of emerging technologies such artificial intelligence and the internet of things to enrich the UAS effectiveness in infrastructure projects, UAS photogrammetry techniques, sensors and economic feasibility according to the context applied.

\section{References}

[1] Q. F. M. Dupont, D. K. H. Chua, A. Tashrif and E. L. Abbott, "Potential Applications of UAV along th Construction Value Chain," in 7th International Conference on Engineering, Project, and production Management, Singapore, 2017. https://www.doi.org/10.1016/j.proeng.2017.03.155

[2] T. Rakha and A. Gorodetsky, "Review of Unmanned Aerial System (UAS) applications in the built environment: Towards automated building inspection procedures using drones," Automation in Construction, vol. 93, pp. 252-264, 2018. https://doi.org/10.1016/j.autcon.2018.05.002

[3] Y. Ham, K. K. Han, J. J. Lin and M. Golparvar-Fard, "Visual monitoring of civil infrastructure systems via camera-equipped Unmanned Aerial Vehicles (UAVs): a review of related works," Visualisation in Engineering, vol. 4, no. 1, 2016. https://doi.org/10.1186/s40327-015-0029-z 
[4] J. Seo, L. Duque and J. Wacker, "Drone-enabled bridge inspection methodology and application," Automation in Construction, vol. 94, pp. 112-126, 2018. https://doi.org/10.1016/j.autcon.2018.06.006

[5] C. Eschmann and T. Wundsam, "Web-based georeferenced 3D inspection and monitoring of bridges with unmanned aircraft systems," Journal of Surveying Engineering, vol. 143, no. 3, p. 04017003, 2017. https://doi.org/10.1061/(ASCE)SU.19435428.0000221

[6] A. Khaloo, D. Lattanzi, K. Cunningham, R. Dell'Andrea and M. Riley, "Unmanned aerial vehicle inspection of the Placer River Trail Bridge through image-based 3D modelling," Structure and Infraestructure Engineering, vol. 14, no. 1, pp. 124-136, 2018. https://doi.org/10.1080/15732479.2017.1330891

[7] G. Morgenthal, H. N. K. J. J. Taraben, P. Debus, M. Helmrich and R. V., "Framework for automated UAS-based structural condition assessment of bridges," Automation in Construction, vol. 97, pp. 77-95, 2019. https://doi.org/10.1016/j.autcon.2018.10.006

[8] M.Diakakis, E. Andreadakis, E. Nikolopoulos, N. Spyrou, M. Gogou, G. Deligiannakis, N. Katsetsiadou, Z. Antoniadis, M. Melaki, A. Georgakopoulos, K. Tsaprouni, J. Kalogiros and E. Lekkas, "An integrated approach of ground and aerial observations in flash flood disaster investigations. The case of the 2017 Mandra flash flood in Greece," International Journal of Disaster Risk Reduction, vol. 33, pp. 290-309, 2019. https://doi.org/10.1016/j.ijdrr.2018.10.015

[9] D. G. W. M. J. A.-Z. A. C. M. C. K. a. Zekkos, "Lessons Learned from the Application of UAV-Enabled Structure-From-Motion Photogrammetry in Geotechnical Engineering," International Journal of Geoengineering Case Histories, vol. 4, no. 4, pp. 254-274, 2018. https://doi.org/10.4417/IJGCH-04-04-03

[10] S. Hamshaw, T. Bryce, D. Rizzo, J. O'Neil-Dunne, J. Frolik and M. Dewoolkar, "Quantifying streambank movement and topography using unmanned aircraft system photogrammetry with comparison to terrestrial laser scanning," River Research and Applications, vol. 33, no. 8, pp. 1354-1367, 2017. https://doi.org/10.1002/rra.3183

[11] L. Inzerillo, G. D. Mino and R. Roberts, "Image-based 3D reconstruction using traditional and UAV datasets for analysis of road pavement distress," Automation in Construction, vol. 96, pp. 457-469, 2018. https://doi.org/10.1016/j.autcon.2018.10.010

[12] X. Huang, X. Liu, Y. Zhang, J. Li, H. Zhang and X. Xing, "Classification Recognition Method of Insulator in Aerial Image Based on the Red-blue Difference and Developed K-means Algorithm," Gaofianya Jishu/High Voltage Engineering, vol. 44, no. 5, pp. 15281534, 2018. https://doi.org/10.13336/j.1003-6520.hve.20180430018

[13] B. Emran, D. Tannant and H. Najjaran, "Low-altitude aerial methane concentration mapping," Remote Sensing, vol. 9, no. 8, p. 823, 2017. https://doi.org/10.3390/rs9080823

[14] M. S. K. de Vitry, J. Rieckermann and J. Leitao, "Sewer inlet localisation in UAV image clouds: Improving performance with multiview detection," Remote Sensing, vol. 10, no. 5, p. 706, 2018. https://doi.org/10.3390/rs10050706

[15] K. Forssén, K. Mäki, M. Räikkönen and R. Molarius, "Resilience of electricity distribution networks against extreme weather conditions," ASCE-ASME Journal of Risk and Uncertainty in Engineering Systems, Part B: Mechanical Engineering, vol. 3, no. 2, p. 021005, 2017. https://doi.org/10.1115/1.4035843 